\title{
ESTIMATION OF LAG TIME AND PEAK DISCHARGE OF FLASH FLOOD OF WADI SUDR IN THE SINAI PENINSULA
}

Abdelazim M. Negm, Abdelazim M. Negm, Mohammed A. Nassar, Eman A. Al-Sayed, Magid M. El-Fiky

\begin{abstract}
Environmental protection of residential areas from flash flood hazard necessitates the prior estimation of $p$ and lag time. Thus estimation of flash flood hydrograph at a watershed outlet is essential for hydrologic flc design and warning system design and operation. Lag time and peak discharge are the most important pa। affect the flash flood hydrograph estimation. Hydrological models employ many different equations to calcı parameters. This paper concerns to calculate losses parameters using measurement data of rainfall and ru hydrographs of Wadi Sudr, Sinai, Egypt. Then watershed modeling system "WMS" is applied using all availi equations and adjusted losses parameters. In addition, peak discharge is estimated using the equations of dimensionless synthetic unit hydrograph. The output hydrograph of these equations is compared to field di propose the best equations to calculate runoff hydrograph. The output results indicate that there is no opti to calculate both of lag time and peak discharge in the study area. As a result, dimensional analysis is use new lag time and peak discharge equations of Wadi Sudr using the measured data of different storms. Th€ equations enable the prediction of the lag time to an accuracy of $7 \%$ error and peak discharge to an accur. than $14 \%$ error which enables Wadi Sudr to be environmentally protected from flash flood hazards
\end{abstract}

